\section{Discussion}

Three different descriptions have been applied to vascular lesions of the gastrointestinal tract in Turner's syndrome-namely haemangioma, telangiectasis, and venous ectasia. ${ }^{4}$ However, reviewing the way these lesions are described by various authors, the terminology seems to overlap greatly, and it may well be that there is one underlying abnormality-namely ectasia of capillaries, venules, and veins. Depending on the preponderance of these three findings, this abnormality may present as a variety of macroscopic appearances.

Diagnosis of this abnormality without resort to laparotomy may be difficult. Telangectasis has been reported as visible via the sigmoidoscope ${ }^{5}$ but this is unlikely to be helpful in patients such as ours with macroscopically visible ectasia only in the distribution of the superior mesenteric vessels. Laparoscopy or culdoscopy would seem to be the most helpful investigation. $^{3}$

Most patients so far reported have each had their first haemorrhage before 20 years of age. In the 20 cases reported by Passarge ${ }^{6}$ most bleeds were selflimiting but 3 were life-threatening and 2 patients, notably both young children, died.

In paediatric practice, a cause for recurrent gastrointestinal blood loss can often be found without resort to surgery. However, explorative laparotomy is occasionally required. Awareness of the condition discussed here may help prevent unnecessary laparotomy in children with known or suspected Turner's syndrome. Having established the diagnosis, subsequent haemorrhages, which are likely to occur, can generally be managed conservatively.

\section{References}

1 Lisser H, Curtis L E, Escamilla R F, Goldberg M B. The syndrome of congenitally aplastic ovaries with sexual infantilism, high urinary gonadotropins, short stature, and other congenital abnormalities. J Clin Endocrinol 1947; 7 : 665-70.

2 Haddad H M, Wilkins L. Congenital anomalies associated with gonadal aplasia. Pediatrics $1959 ; 23$ : 885-902.

${ }^{3}$ Schultz L S, Assimacopoulos C A, Lillehei R C. Turner's syndrome with associated gastrointestinal haemorrhage. A case report. Surgery $1970 ; 68$ : 485-8.

4 Redondo D, Swenson O. Gastrointestinal bleeding associated with gonadal aplasia. Surgery $1967 ; 61$ : 285-7.

5 Rosen K, Sirota D K, Marinoff S C. Gastrointestinal bleeding in Turner's syndrome. Ann Intern Med 1967; 67: 145-50.

6 Passarge E. Gastrointestinalblutung beim TurnerSyndrom infolge Telangiektasien in der Darmwand. Dtsch Med Wochenschr 1968; 93: 204-6.

Correspondence to D M Burge FRCS, Department of Paediatric Surgery, Royal Alexandra Hospital for Children, Camperdown 2050, Sydney, New South Wales, Australia.

Received 7 October 1980

\title{
Synovial haemangioma presenting as monarticular arthritis of the knee
}

\author{
W L HAWLEY AND BARBARA M ANSELL \\ Juvenile Rheumatism Unit, Canadian Red Cross Memorial Hospital, Taplow
}

SUMMARY Two children with haemangioma of the synovial membrane presenting as swelling of a knee joint are described; in one patient this was associated with epiphyseal overgrowth. This condition should be considered if bloody synovial fluid is obtained and clotting studies are normal.

Disease in a single joint in a child requires full appraisal as quickly as possible. ${ }^{1}$ Since the decline in tuberculosis, persistent synovitis in one knee is often attributed to juvenile chronic arthritis. There are however a number of conditions, each requiring surgical treatment, which should be excluded. The purpose of this paper is to draw attention to synovial haemangioma.

\section{Case reports}

Case 1. A 14-month-old white boy developed sudden swelling of the right knee with no preceding trauma. He was admitted to a hospical where aspiration of the joint under general anaesthesia produced $24 \mathrm{ml}$ frank blood. A plaster cylinder was applied to the leg and left on for 3 weeks. When the plaster was removed the knee was still swollen and there was a $30^{\circ}$ flexion deformity, so further investigations for evidence of infection, a bleeding tendency, or juvenile arthritis, were instituted. These included erythrocyte sedimentation rate (ESR), prothrombin and kaolin-cephalin clotting time (KCCT), antinuclear antibody, and slit-lamp examination of the eyes. All results were normal, as was the $x$-ray film. 
When referred here 3 months later his condition had improved so that he had only $15^{\circ}$ loss of full extension and slight muscle wasting. One week later the right knee suddenly became swollen. At this time the knee had fixed flexion of $30^{\circ}$, there was soft tissue swelling, and an effusion. No other joint was affected. General examination was normal and there was no evidence of cutaneous haemangiomata. The knee was aspirated and again this produced heavily bloodstained fluid. Once more investigations were normal with the ESR $5 \mathrm{~mm} / 1 \mathrm{st}$ hour, haemoglobin $11.6 \mathrm{~g} / \mathrm{dl}$, white blood count $9.3 \times 10^{9} / \mathrm{l}$, platelets $350 \times 10^{9} / \mathrm{l}$, prothrombin time, KCCT, and thrombin time unremarkable. In view of the normal coagulation screen it was felt the most likely cause of the recurrent episodes of bleeding was a vascular abnormality in the knee. Arthrotomy was performed and a vascular tumour was found within the intercondylar notch. This was removed and was shown histologically to be a cavernous haemangioma. By the time he was discharged the range of movement was 0 to $90^{\circ}$. At 6 months follow-up there had been no further swelling and clinically there was no evidence of soft tissue swelling, there was slight loss of full extension (about $3^{\circ}$ ), but full flexion had returned and the child was functioning normally.

Case 2. A white girl first developed painful swelling of the left knee associated with a minor injury at age 18 months. This settled, but was followed by episodes of painful swelling of the knee, occurring three or four times a year. On each occasion the swelling developed in only a few minutes and without preceding trauma. She was referred here when aged 5 because of an episode of persistent swelling for 2 months and a provisional diagnosis of juvenile chronic arthritis. Joint examination showed the only abnormality to be in the left knee where, in addition to soft tissue swelling, there was bony overgrowth associated with the left leg being $2 \mathrm{~cm}$ longer than the right. $X$-ray films of the knees showed enlargement and roughening of the epiphyses on the affected side (Figure). There was no abnormality on general examination and in particular no evidence of cutaneous haemangiomata. Investigations showed that bleeding, clotting, and prothrombin times were normal; the synovial fluid aspirated from the knee was blood-stained and contained $5 \mathrm{~g} / 100 \mathrm{ml}(50 \mathrm{~g} / \mathrm{l})$ protein. To find out the cause of the synovitis, a biopsy was done and this showed there was a slight increase in the number of synovial cells, the presence of inflammatory cells, and a great deal of iron staining. No definitive diagnosis was made at this stage and, after biopsy, function returned to normal. However, 5 years later recurrent episodes of severe swelling occurred with loss of function and persistent

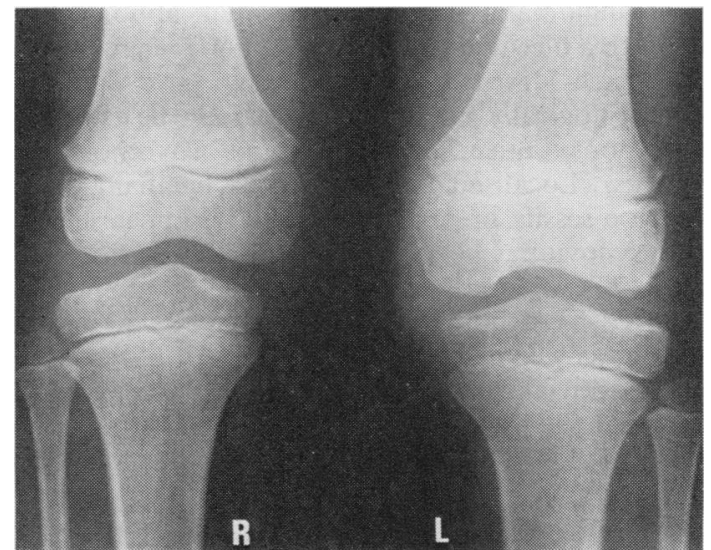

Figure (Case 2.) Radiograph of both knees 31 years after onset of symptoms showing enlargement and irregularity of the epiphyses on the left side.

soft tissue swelling, so at age 12 years an arthrotomy was performed which showed a haemangioma of the synovium lining the infrapatellar fat pad. The haemangioma was excised together with the synovium, which showed pronounced hypertrophy. The histology of the excised synovium suggested pigmented villonodular synovitis, but it was considered that this must be secondary to bleeding from the haemangioma. Postoperative mobilisation of the knee was slow, but at follow-up later the range of movement was 0 to $120^{\circ}$ and both legs were of the same length. There has been no recurrence of swelling in a 10-year follow-up period.

\section{Discussion}

Synovial haemangioma is a rare condition; it generally affects the knee joint although it can occur at other sites. Pain, swelling, and limitation of movement are the most common presenting symptoms. In $75 \%$ of cases these occur during childhood, often in the first 5 years of life. ${ }^{2}$ There may be a history of preceding trauma. The clinical findings are non-specific, but the most common findings are soft tissue swelling and loss of full range of movement; if an effusion is present the aspirate is blood-stained. Epiphyseal overgrowth and increased limb length mimicking chronic inflammation can occur if the condition is long-standing. Further confusion arises with the development of quadriceps atrophy associated with impaired function. In a few cases vascular changes, telangiectasia, naevus, or haemangioma of the overlying skin have been noted. Very rarely intra-articular haemorrhage occurs if intravascular coagulation within cutaneous 
haemangiomata and other vascular abnormalities leads to a bleeding tendency (Klippel-Trenaunay and Kasabach-Merritt syndromes). ${ }^{3-5}$

Histologically haemangiomata may be capillary, cavernous, mixed capillary and cavernous, or venous. Localised intra-articular haemangiomata may be sessile or pedunculated. The appearance of the synovium, both clinically and histologically, may resemble that of pigmented villonodular synovitis. Although the evidence from animal studies as well as the human models of haemophilia and synovial haemangiomata does not generally bear out the hypothesis that pigmented villonodular synovitis is due to recurrent intra-articular haemorrhage, ${ }^{6} 3$ cases of synovial haemangioma in childhood have been reported in which the synovium was histologically indistinguishable from pigmented villonodular synovitis. ${ }^{7}$ It is important that a search for haemangioma be made whenever a histological report of pigmented villonodular synovitis is obtained on a synovial biopsy in a child.

Synovial haemangiomata may be readily treated by surgical excision and this condition must be considered in the differential diagnosis of monarticular arthritis in childhood.

\section{References}

1 Swann M. Monoarthritis. In: Clinics in rheumatic diseases. Vol. 2. Philadelphia: Saunders, 1976: 369-86.

2 Moon N F. Synovial hemangioma of the knee joint. Clin Orthop 1973; 90: 183-90.

${ }^{3}$ Klippel M, Trenaunay P. Du noevus variqueaux osteohypertrophique. Arch Gen Med (Paris) 1900; 1 : 641-72.

4 Kasabach H H, Merritt K K. Capillary haemangioma with extensive purpura. Report of a case. Am J Dis Child 1940; 59: 1063-70.

5 Resnick D, Oliphant M. Hemophilia-like arthropathy of the knee associated with cutaneous and synovial hemangiomas. Radiology 1975 ; 114 : 323-6.

- Docken W P. Pigmented villonodular synovitis. A review with illustrative case reports. Semin Arthritis Rheum 1979; 9: 1-22.

7 Bobechko W P, Kostuik J P. Childhood villonodular synovitis. Can J Surg 1968; 11 : 480-6.

Correspondence to Dr B M Ansell, Juvenile Rheumatism Unit, Canadian Red Cross Memorial Hospital, Taplow, Maidenhead, Berks SL6 0HN.

Received 28 October 1980

\title{
Infantile flexural seborrhoeic dermatitis. Neither biotin nor essential fatty acid deficiency
}

\author{
M ERLICHMAN, R GOLDSTEIN, E LEVI, A GREENBERG, AND S FREIER
} Department of Paediatrics, and Laboratories of the Institute of Gastroenterology, Shaare Zedek Medical
Centre, Jerusalem

SUMMARY The allegedly beneficial effect of biotin in the treatment of infantile 'flexural' seborrhoeic dermatitis was evaluated in a double-blind controlled study. No beneficial effect could be confirmed, and it is therefore unlikely that this disease is caused by biotin deficiency. Nor could this scaly dermatitis be ascribed to an essential fatty acid deficiency. Serum and adipose tissue fatty acids resembled each other and reflected the fatty acid composition of the diet.

Infantile seborrhoeic dermatitis is a self-limiting disease which affects the flexures and creases of the skin without any systemic manifestation. Its aetiology is unknown and the adjective 'seborrhoeic' is inappropriate as the sebaceous glands are not affected in the disease process. A paper in this journal ${ }^{1}$ claimed that biotin was effective in its treatment.
The purpose of this investigation was (1) to perform a double-blind controlled trial with biotin, and (2) to evaluate the possibility that a deficiency of essential fatty acids is the cause of the scaly dermatitis. $^{2}$

\section{Patients and methods}

Infants were diagnosed as suffering from seborrhoeic dermatitis if they showed the following features: (1) Onset before age 3 months. (2) Involvement of the flexures, skin creases, including the postauricular region, but not the cheeks. (3) Spontaneous disappearance by 8 months. (4) No pruritus.

The purpose of the double-blind trial was explained to the mothers. Twenty infants received one 5-mg dose orally of biotin or a placebo (glucose) daily for 2 weeks. The parents were asked to stop all topical treatment during the trial. The infants were 